\title{
Pengaruh Budaya 5R dan Kinerja Karyawan terhadap Lingkungan Kerja di Sinter Plant PT.XYZ
}

\author{
Muhamad Bob Anthony \\ Teknik Industri Universitas Serang Raya \\ Jalan Raya Cilegon Km.5 Banten 42162, Indonesia \\ Email : tonipbmti@gmail.com

\section{The Influence of 5R Culture and Employee's Performance on the Work Environment at the Sinter Plant of PT.XYZ}

Dikirimkan: 08, 2020. Diterima: 09, 2020. Dipublikasikan: 09, 2020

\begin{abstract}
PT. XYZ is one of the large and multinational companies engaged in steel production in Indonesia and in the first half of 2019 PT. XYZ faces a challenge that is the many employees in the sinter plant do not implement the $5 R$ culture. Sinter plant is the main supplier plant for the blast furnace plant at $P T$. XYZ which functions to combine a raw material mixture at high temperatures to produce a product known as sinter ore. This research was conducted at PT. XYZ. The data obtained was then processed and analyzed using the SPSS version 26 program. Based on the results of data processing and analysis, it was found that all indicators used in this study had good validity and reliability. The results of data processing and analysis in this study also found that $5 R$ culture (X1) and employee performance (X2) had an influence on the work environment $(Y)$.
\end{abstract}

Keywords-5R Culture, Employee Performance, Work Environment.

\begin{abstract}
Abstrak- PT. XYZ adalah salah satu perusahaan besar dan multinasional yang bergerak di bidang produksi baja di Indonesia dan pada semester pertama tahun 2019 PT. XYZ menghadapi tantangan yaitu banyaknya karyawan di sinter plant yang tidak melaksanakan budaya 5R. Sinter plant merupakan plant pemasok utama untuk blast furnace plant di PT. XYZ yang berfungsi untuk menggabungkan suatu raw material mixture pada temperatur tinggi sehingga menghasilkan produk yang dikenal dengan nama sinter ore. Penelitian ini dilakukan di sinter plant PT. XYZ. Data yang didapat kemudian diolah dan dianalisis menggunakan program SPSS versi 26. Berdasarkan hasil pengolahan data dan analisa tersebut didapat bahwa semua indikatorindikator yang digunakan dalam penelitian ini memiliki keabsahan (validitas) dan keandalan (reliabilitas) yang baik. Hasil pengolahan data dan analisa dalam penelitian ini juga mendapatkan bahwa budaya 5R (X1) dan kinerja karyawan (X2) mempunyai pengaruh terhadap lingkungan kerja (Y).
\end{abstract}

Kata kunci-Budaya 5R, Kinerja Karyawan, Lingkungan Kerja.

\section{PENDAHULUAN}

Kegiatan proses produksi sangat dipengaruhi oleh budaya kerja. Budaya kerja adalah suatu sifat kebiasaan dalam suatu kelompok yang tercermin dalam sikap menjadi perilaku tindakan yang terwujud sebagai kerja. Salah satu budaya kerja yang diterapkan untuk memperbaiki kualitas lingkungan kerja adalah budaya kerja 5S (Seiri, Seiton, Seiso, Seiketsu, dan Shitsuke). Budaya kerja 5S tidak hanya baik digunakan untuk melakukan perbaikan di lingkungan kerja, akan tetapi juga dapat memperbaiki cara berpikir karyawan terhadap pekerjaannya [1].
Budaya kerja 5S adalah serangkaian kegiatan sehari-hari di tempat kerja seperti kegiatan pemisahan barang-barang, penataan, pembersihan, pemeliharaan dan pembiasaan yang diperlukan untuk melaksanakan pekerjaan menjadi lebih baik [2].

5S merupakan metode penataan lingkungan kerja yang berasal dari Jepang. $5 \mathrm{~S}$ ini merupakan singkatan dari Seiri, Seiton, Seiso, Seiketsu, dan Shitsuke yang secara bahasa Indonesia dapat diartikan sebagai Ringkas, Rapi, Resik, Rawat, dan Rajin (5R). Pada dasarnya, 5R merupakan proses perubahan perilaku melalui perubahan tempat kerja dengan menerapkan penataan dan 
kebersihan tempat kerja. Kondisi tempat kerja mencerminkan perlakuan seseorang terhadap pekerjaannya dan perlakuan terhadap pekerjaan mencerminkan sikapnya terhadap pekerjaan [3].

Budaya kerja 5R akan berdampak pada efektivitas, efisiensi, produktivitas dan keselamatan dalam bekerja. Selain itu budaya kerja 5R adalah salah satu cara untuk menciptakan suasana kerja yang nyaman di suatu lingkungan kerja [4].

Kinerja adalah hasil kerja yang konkrit, dapat diamati dan dapat diukur sehingga kinerja merupakan hasil kerja yang dicapai karyawan dalam pelaksanaan tugas yang berdasarkan ukuran dan waktu yang telah ditentukan [5].

Kinerja karyawan akan mempengaruhi pencapaian target perusahaan. Jika kinerja karyawan baik maka pencapaian target yang diinginkan perusahaan juga akan tercapai. Banyak faktor yang mempengaruhi kinerja karyawan di suatu perusahaan. Salah satu faktor yang juga berpengaruh terhadap kinerja karyawan adalah faktor lingkungan kerja. Lingkungan kerja yang yang nyaman, aman, kondisi sarana dan prasarana serta fasilitas karyawan yang terpenuhi di perusahaan diperlukan untuk mencapai tujuan perusahaan dikarenakan akan mendorong karyawan untuk melakukan pekerjaan dengan optimal [6].

Lingkungan kerja merupakan bagian komponen yang sangat penting bagi karyawan dalam melakukan aktivitas bekerja. Jika memperhatikan lingkungan kerja dengan baik atau dapat menciptakan kondisi kerja yang mampu memberikan motivasi untuk bekerja, maka akan membawa pengaruh terhadap kegairahan atau semangat karyawan dalam bekerja. Pengertian lingkungan kerja disini adalah segala sesuatu yang ada disekitar para karyawan dan yang dapat mempengaruhi dirinya dalam menjalankan tugas-tugas yang dibebankan misalnya kebersihan, musik, penerangan dan lainlain [7].

PT. XYZ adalah salah satu perusahaan besar dan multinasional yang bergerak di bidang produksi baja di Indonesia. Salah satu plant yang mempunyai peran besar di PT. XYZ adalah sinter plant. Sinter plant merupakan plant pemasok utama untuk blast furnace yang berfungsi untuk menggabungkan suatu raw material mixture pada temperatur tinggi sehingga menghasilkan produk yang dikenal dengan nama sinter ore.

Sinter plant telah memiliki program 5R, memiliki karyawan yang bertanggung jawab terhadap program 5R dan juga memiliki laporan untuk penilaian $5 \mathrm{R}$. Laporan $5 \mathrm{R}$ ini dibuat oleh penanggung jawab $5 \mathrm{R}$ dalam bentuk laporan harian yang harus diisi oleh masing - masing unit kerja.

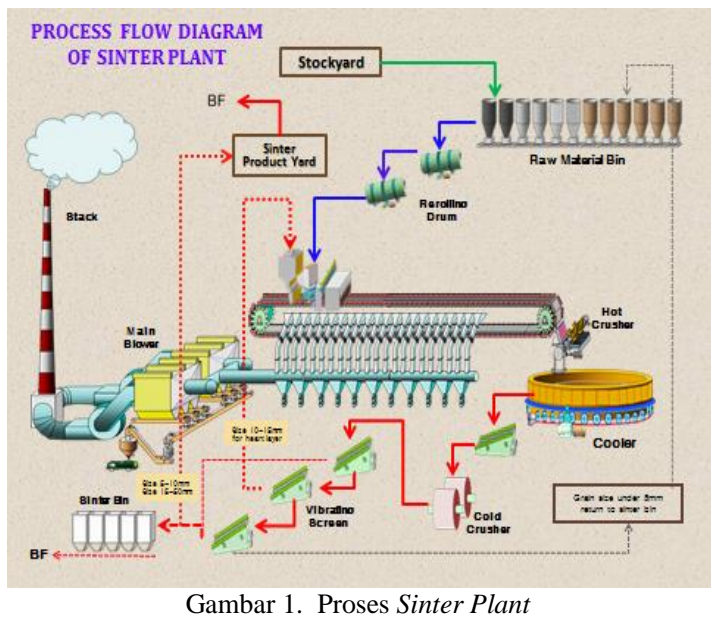

Pelaksanaan 5R di sinter plant PT. XYZ masih sering diabaikan oleh para karyawan karena dianggap sebagai hal yang kecil. Masalah ini didukung dengan laporan $5 \mathrm{R}$ perusahaan yang menyatakan bahwa 41,67 \% karyawan masih memiliki perilaku 5R yang kurang baik, 29,16\% yang memiliki perilaku 5R cukup baik, 16,67\% yang memiliki perilaku 5R baik, $10,42 \%$ yang memiliki perilaku 5R sangat baik. Perilaku 5R yang kurang baik dapat berisiko terjadi penurunan kinerja, penurunan produktivitas kerja, kurangnya akurasi dalam bekerja, pemborosan waktu, meningkatnya kecelakaan kerja dan menimbulkan lebih cepat kelelahan kerja.

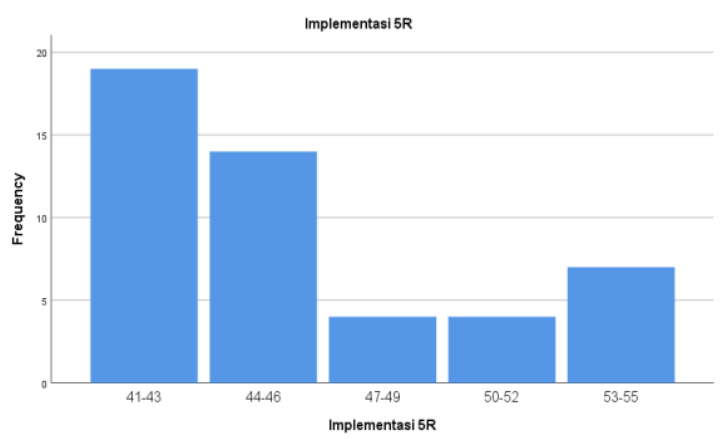

Gambar 2. Bar charts laporan 5R sinter plant PT. XYZ

Penelitian ini dilakukan untuk melihat pengaruh perilaku budaya $5 \mathrm{R}$ (X1) terhadap lingkungan kerja $(\mathrm{Y})$, pengaruh kinerja karyawan (X2) terhadap lingkungan kerja (Y) dan pengaruh perilaku budaya 5R (X1) dan kinerja karyawan (X2) secara bersama-sama terhadap lingkungan kerja (Y) di sinter plant PT. PT. XYZ.

\section{METOdologi PENELITIAN}


Objek dalam penelitian ini difokuskan hanya pada perilaku budaya 5R (X1), kinerja karyawan (X2) dan lingkungan kerja (Y) di sinter plant PT. $\mathrm{XYZ}$.

Penelitian ini merupakan penelitian kausal komparatif yaitu penelitian yang menyatakan hubungan satu variabel menyebabkan variabel lainnya. Variabel yang dipengaruhi adalah variabel terikat yaitu lingkungan kerja (Y) dan variabel yang mempengaruhi adalah variabel bebas yaitu budaya 5R (X1) dan kinerja karyawan (X2).

Pengumpulan data dilakukan dengan menggunakan metode pemilihan tidak acak yaitu pengambilan sampel yang tidak semua sampel dalam populasi diberi peluang yang sama untuk menjadi anggota sampel. Metode pemilihan sampel secara tidak acak yang digunakan yaitu pengambilan sampel yang dilakukan dengan mengambil sampel dari populasi berdasarkan suatu kriteria tertentu. Kriteria yang digunakan dalam penelitian ini adalah berdasarkan jatah tertentu atau kuota sampel yang merupakan teknik untuk menentukan sampel dan populasi yang mempunyai ciri-ciri atau karakteristik untuk tertentu sampai jumlah (kuota) yang diinginkan. Misalnya, jumlah sampel ditentukan adalah 48, maka penulis dapat memilih sampel secara bebas sesuai dengan karakteristik yang ditentukan.

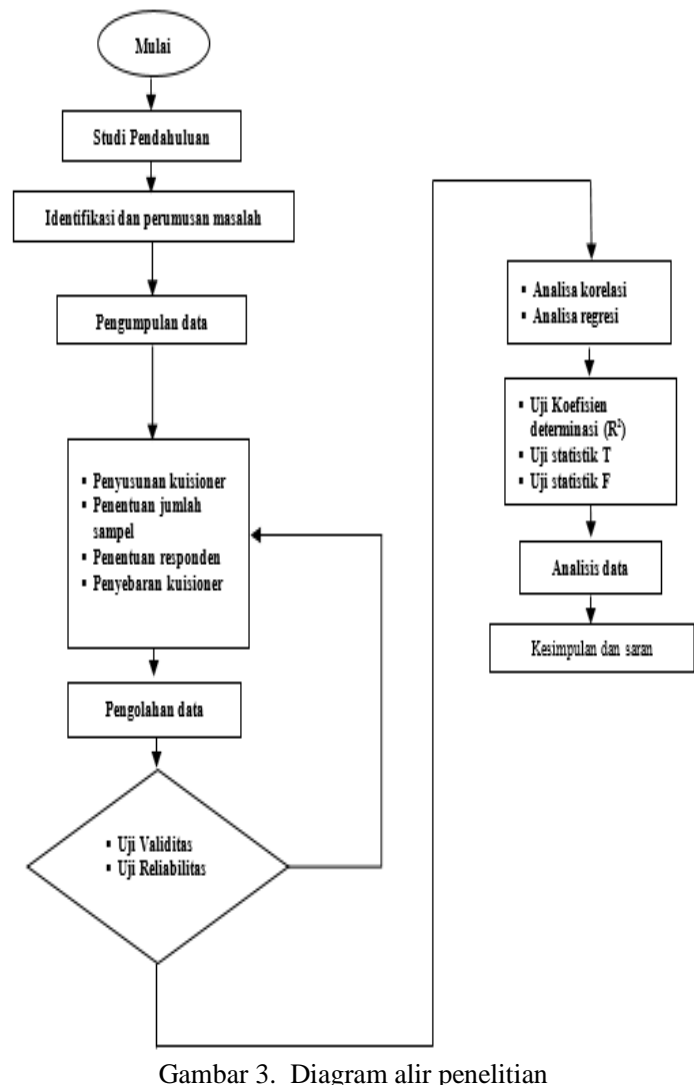

\section{A. Uji Validitas dan Uji Reliabilitas}

Uji validitas dan reliabilitas dilakukan untuk memastikan alat ukur tersebut merupakan alat ukur yang akurat dan dapat dipercaya. Validitas menunjukkan sejauh mana suatu alat pengukur itu mengukur apa saja yang ingin diukur. Sedangkan reliabilitas menunjukkan sejauh mana suatu hasil pengukuran relatif konsisten apabila pengukuran terhadap aspek yang sama pada alat ukur yang sama [8].

Uji validitas digunakan untuk menunjukkan ukuran yang benar-benar mengukur apa yang hendak diukur [7].

Dasar pengambilan keputusan adalah :

a. Jika $r$ hitung $>r$ tabel, maka butir pertanyaan tersebut valid

b. Jika $\mathrm{r}$ hitung < $\mathrm{r}$ tabel, maka butir pertanyaan tersebut tidak valid.

Validitas adalah suatu ukuran yang menunjukkan tingkat-tingkat kevalidan dan kesahihan suatu instrument [9].

Uji validitas dapat dihitung dengan rumus sebagai berikut:

$r_{x y}=\frac{n\left(\sum X Y\right)-\left(\sum X\right)\left(\sum Y\right)}{\sqrt{\left[n\left(\sum X^{2}\right)-\left(\sum X\right)^{2} \mid n\left(\sum Y^{2}\right)-\left(\sum Y\right)^{2}\right]}}(1)$

Keterangan:

$r_{x y} \quad=$ koefisien korelasi suatu butir/item

$\mathrm{N} \quad$ jumlah subyek

$\mathrm{X}=$ skor suatu butir/item

$\mathrm{Y}=$ skor total

Nilai $r$ kemudian dikonsultasikan dengan $r_{\text {tabel }}$ $\left(r_{\text {kritis }}\right)$. Bila $r_{\text {hitung }}$ dari rumus di atas lebih besar dari $r_{\text {tabel }}$ maka butir tersebut valid, dan sebaliknya.

Secara umum, jika nilai nilai total korelasi pearson antara data-data yang yang dikoreksi > 0.2 dan Probabilitasnya dibawah 0.01 (signifikan) maka dapat dikatakan valid [8].

Uji reliabilitas merupakan alat untuk mengukur kehandalan yang dibuat oleh peneliti. Uji ini digunakan beberapa kali untuk mengukur objek yang sama dengan menghasilkan jawaban yang sama. Pengujian reliabilitas instrument yang digunakan adalah dengan menggunakan program SPSS 26. Reliabilitas menunjukkan suatu pengertian bahwa sesuatu instrumen cukup dapat dipercaya atau digunakan sebagai alat pengumpulan data karena instrumen tersebut sudah baik [9].

Pengujian reliabilitas dilakukan dengan menguji skor antar item untuk menguji tingkat reliabilitas, Dalam menguji reliabilitas digunkaan 
uji konsistensi internal dengan menggunakan rumus Alpha Cronbach sebagai berikut.

$$
r_{11}=\left[\frac{k}{k-1}\right]\left[1-\frac{\sum \sigma_{b}^{2}}{V_{t}^{2}}\right]
$$

Keterangan:

$r_{11}=$ Reliabilitas instrumen

$\mathrm{k} \quad=$ Banyaknya butir pertanyaan atau

banyaknya soal

$\sum \sigma_{b}^{2}=$ Jumlah varian butir/item

Reliabilitas diukur dengan menggunakan uji statistik Nilai Cronbach Alpha. Jika nilai Cronbach Alpha > 0.6 maka hal ini menunjukkan bahwa pengukuran yang digunakan handal (Reliabel). Nilai Cronbach Alpha dihitung dengan Persamaan 2 [8].

\section{B. Analisis Korelasi}

Dalam analisis kolerasi, yang dicari adalah koefisien kolerasi atau angka yang menyatakan derajat hubungan antara variabel independen $(\mathrm{X})$ dengan variabel dependen (Y) atau untuk mengetahui kuat atau lemahnya hubungan antara variabel independen dengan variabel dependen. Pada penelitian ini data yang dinilai adalah data variabel bebas yaitu budaya 5R, kinerja karyawan dan variabel terikat yaitu lingkungan kerja [10].

Pedoman untuk memberikan interpretasi koefisien korelasi adalah sebagai berikut:

$$
r=\frac{\mathrm{n} \Sigma \mathrm{xy}-(\Sigma \mathrm{x})(\Sigma \mathrm{y})}{\sqrt{\left\{\mathrm{n} \Sigma \mathrm{x}^{2}-(\Sigma \mathrm{x})^{2}\right\}\left\{\mathrm{n} \Sigma \mathrm{y}^{2}-(\Sigma \mathrm{y})^{2}\right\}}}
$$

Dimana :

$\mathrm{n} \quad=$ Banyaknya Pasangan data $\mathrm{X}$ dan $\mathrm{Y}$

$\Sigma \mathrm{x} \quad=$ Total Jumlah dari Variabel $\mathrm{X}$

$\Sigma y \quad=$ Total Jumlah dari Variabel Y

$\Sigma \mathrm{x}^{2} \quad=$ Kuadrat dari Total Jumlah Variabel $\mathrm{X}$

$\Sigma \mathrm{y}^{2} \quad=$ Kuadrat dari Total Jumlah Variabel Y

$\Sigma x y=$ Hasil Perkalian dari Total Jumlah

Variabel X dan Variabel Y

TABEL I

PEDOMAN INTERPRESTASI TINGKAT KORELASI

\begin{tabular}{|c|c|}
\hline $\begin{array}{c}\text { Interval Koefisien } \\
\text { Korelasi (r) }\end{array}$ & $\begin{array}{c}\text { Tingkat } \\
\text { Hubungan }\end{array}$ \\
\hline $0,00-0,19$ & Sangat Rendah \\
\hline $0,20-0,39$ & Rendah \\
\hline $0,40-0,59$ & Sedang \\
\hline $0,60-0,79$ & Kuat \\
\hline $0,80-1,00$ & Sangat Kuat \\
\hline
\end{tabular}

\section{Analisa Regresi}

Analisa regresi pada dasarnya adalah studi mengenai ketergantungan variabel terikat dengan satu atau lebih variabel variabel penjelas atau bebas, dengan tujuan untuk memperkirakan dan atau memprediksi rata-rata populasi atau nilai rata-rata variabel terikat berdasarkan nilai variabel bebas yang diketahui. Regresi sederhana untuk menguji pengaruh satu variabel bebas (metrik) terhadap satu variabel terikat (metrik). Dalam analisa regresi, selain mengukur kekuatan hubungan antara dua variabel, juga menunjukkan arah hubungan antara variabel terikat dengan variabel bebas. Secara statistik, ketepatan fungsi regresi sampel dalam menaksir nilai aktual ini setidaknya dapat diukur dari nilai koefisien determinasi $\left(\mathrm{R}^{2}\right)$, nilai statistik $\mathrm{F}$ dan nilai statistik $\mathrm{t}[8]$.

\section{Analisis Koefisien Determinasi (R2)}

Koefisien determinasi $\left(\mathrm{R}^{2}\right)$ mengukur seberapa jauh kemampuan model dalam menerangkan variasi variabel dependen. Nilai koefisien determinasi adalah antara nol dan satu. Nilai $\mathrm{R}^{2}$ yang kecil berarti kemampuan variabel-variabel independen dalam menjelaskan variasi variabel dependen amat terbatas. Nilai yang mendekati satu berarti variabel-variabel independen memberikan hampir semua informasi yang dibutuhkan untuk memprediksi variasi variabel dependen [8].

Besarnya koefisien determinasi dapat dihitung dengan menggunakan rumus sebagai berikut:

$$
\mathrm{Kd}=\mathrm{R}^{2} \times 100 \%
$$

Keterangan :

$\mathrm{Kd}=$ Koefisien determinasi

$\mathrm{R}^{2} \quad=$ Koefisien korelasi

Kriteria untuk analisis koefisien determinasi adalah:

a. Jika Kd mendeteksi nol (0), maka pengaruh variabel independent terhadap variabel dependent lemah.

b. Jika Kd mendeteksi satu (1), maka pengaruh variabel independent terhadap variabel dependent kuat.

\section{E. Uji Signifikan simultan (Uji Statistik F)}

Uji statistik $F$ pada dasarnya menunjukkan apakah semua variabel bebas yang dimasukkan dalam model mempunyai pengaruh secara bersama-sama terhadap variabel terikat. Bila Nilai F mempunyai probabilitas $<0.05$ dan signifikan maka semua variabel bebas secara serentak dan signifikan mempengaruhi variabel [8]. 
Jurnal Media

Teknik dan

Sistem Industri

\section{F. Uji Signifikan Parameter (Uji Statistik t)}

Uji statistik $\mathrm{t}$ pada dasarnya menunjukkan seberapa jauh pengaruh satu variabel penjelas atau bebas secara tepat dalam menerangkan variasi variabel terikat. Jika Nilai t mempunyai probabilitas $<0.05$ dan signifikan maka suatu variabel bebas secara tepat mempengaruhi variabel terikat [8].

\section{HASIL PENELITIAN}

\section{A. Analisa Deskriptif}

Analisa deskriptif program SPSS untuk jumlah data masing-masing variabel (N) sebanyak 48 data didapat informasi, sebagaimana terlihat pada Tabel II, III, IV dan V.

TABEL II

KARAKTERISTIK RESPONDEN

\begin{tabular}{|c|c|c|c|}
\hline No & Jenis Kelamin & Jumlah & Persentasi (\%) \\
\hline 1 & Laki-laki & 48 & $100 \%$ \\
\hline 2 & Perempuan & 0 & $0 \%$ \\
\hline \multicolumn{2}{|c|}{ Jumlah } & 48 & $100 \%$ \\
\hline
\end{tabular}

TABEL III

UMUR RESPONDEN

\begin{tabular}{|c|c|c|c|}
\hline No & Umur (Tahun) & Jumlah & $\begin{array}{c}\text { Persentasi } \\
(\%)\end{array}$ \\
\hline 1 & $20-35$ & 31 & $64.58 \%$ \\
\hline 2 & $36-50$ & 17 & $34.51 \%$ \\
\hline \multicolumn{2}{|c|}{ Jumlah } & 48 & $100 \%$ \\
\hline
\end{tabular}

TABEL IV

TINGKAT PENDIDIKAN RESPONDEN

\begin{tabular}{|c|c|c|c|}
\hline No & Pendidikan & Jumlah & Persentasi (\%) \\
\hline 1 & SMA & 34 & $70.83 \%$ \\
\hline 2 & Akademi / DIII & 6 & $12.50 \%$ \\
\hline 3 & S1 & 8 & $16.67 \%$ \\
\hline \multicolumn{2}{|c|}{ Jumlah } & 48 & $100 \%$ \\
\hline
\end{tabular}

TABEL V

MASA KERJA RESPONDEN

\begin{tabular}{|c|c|c|c|}
\hline No & $\begin{array}{c}\text { Masa Kerja } \\
\text { (Tahun }\end{array}$ & Jumlah & Persentasi (\%) \\
\hline 1 & $<2$ & 1 & $2.08 \%$ \\
\hline 2 & $>2$ & 3 & $6.25 \%$ \\
\hline 3 & $>5$ & 44 & $91.66 \%$ \\
\hline \multicolumn{2}{|c|}{ Jumlah } & 48 & $100 \%$ \\
\hline
\end{tabular}

\section{B. Uji Validitas}

Untuk menentukan hasil dari tiap butir instrument variabel budaya $5 \mathrm{R}$, kinerja karyawan dan lingkungan kerja menggunakan rumus koefisiensi korelasi product moment, dengan membandingkan $\mathrm{r}$ hitung dan $\mathrm{r}$ tabel untuk tingkat kesalahan 5\% dengan $\mathrm{N}=48$ diperoleh $\mathrm{r}$ tabel $=$ 0.278 .

TABEL VI

UJI VALIDITAS VARIABEL BUDAYA 5R (X1)

\begin{tabular}{|c|c|c|c|c|c|}
\hline & $\begin{array}{c}\text { Pearson } \\
\text { Correlation }\end{array}$ & $\begin{array}{c}\text { Sig. (2- } \\
\text { tailed) }\end{array}$ & $\mathbf{N}$ & $\begin{array}{c}\text { rtabel } \\
\mathbf{5 \%}\end{array}$ & Keterangan \\
\hline X1_P1 & $.550^{* *}$ & .000 & 48 & .278 & Valid \\
\hline X1_P2 & $.601^{* *}$ & .000 & 48 & .278 & Valid \\
\hline X1_P3 & $.680^{* *}$ & .000 & 48 & .278 & Valid \\
\hline X1_P4 & $.554^{* *}$ & .000 & 48 & .278 & Valid \\
\hline X1_P5 & $.667^{* *}$ & .000 & 48 & .278 & Valid \\
\hline X1_P6 & $.613^{* *}$ & .000 & 48 & .278 & Valid \\
\hline Total_X1 & 1 & & 48 & & \\
\hline
\end{tabular}

TABEL VII

UJI VALIDITAS VARIABEL KINERJA KARYAWAN (X2)

\begin{tabular}{|c|c|c|c|c|c|}
\hline & $\begin{array}{c}\text { Pearson } \\
\text { Correlation }\end{array}$ & $\begin{array}{c}\text { Sig. (2- } \\
\text { tailed) }\end{array}$ & $\mathbf{N}$ & $\begin{array}{c}\text { rtabel } \\
\mathbf{5 \%}\end{array}$ & Keterangan \\
\hline X2_P7 & $.314 *$ & .000 & 48 & .278 & Valid \\
\hline X2_P8 & $.502 * *$ & .000 & 48 & .278 & Valid \\
\hline X2_P9 & $.325 *$ & .000 & 48 & .278 & Valid \\
\hline X2_P10 & $.463 * *$ & .000 & 48 & .278 & Valid \\
\hline X2_P11 & $.661 * *$ & .000 & 48 & .278 & Valid \\
\hline X2_P12 & $.630 * *$ & .000 & 48 & .278 & Valid \\
\hline Total_X2 & 1 & & 48 & & \\
\hline
\end{tabular}


TABEL VIII

UJI VALIDITAS VARIABEL LINGKUNGAN KERJA (Y)

\begin{tabular}{|c|c|c|c|c|c|}
\hline & $\begin{array}{c}\text { Pearson } \\
\text { Correlation }\end{array}$ & $\begin{array}{c}\text { Sig. (2- } \\
\text { tailed) }\end{array}$ & $\mathbf{N}$ & $\begin{array}{c}\text { rtabel } \\
\mathbf{5 \%}\end{array}$ & Keterangan \\
\hline Y_P13 & $.387^{* *}$ & .007 & 48 & .278 & Valid \\
\hline Y_P14 & $.426^{* *}$ & .003 & 48 & .278 & Valid \\
\hline Y_P15 & $.647^{* *}$ & .000 & 48 & .278 & Valid \\
\hline Y_P16 & $.647^{* *}$ & .000 & 48 & .278 & Valid \\
\hline Y_P17 & $.446^{* *}$ & .002 & 48 & .278 & Valid \\
\hline Y_P18 & $.448^{* *}$ & .001 & 48 & .278 & Valid \\
\hline Total_Y & 1 & & 48 & & \\
\hline
\end{tabular}

Berdasarkan data hasil uji validitas pada Tabel VI, VII dan VIII, dapat dijelaskan bahwa dari 48 item data budaya 5R (X1), kinerja karyawan (X2) dan lingkungan kerja $(\mathrm{Y})$ dinyatakan valid pada total korelasi pearson antara masing-masing data yang dikoreksi yaitu budaya 5R (X1), kinerja karyawan (X2) dan lingkungan kerja (Y) adalah lebih besar dari 0.2 dan signifikannya 0 (nol) atau di bawah 0.01 .

\section{Uji Reliabilitas}

Uji reliabilitas digunakan untuk menunjukkan bahwa instrument yang digunakan memiliki konsisten dalam hasil pengukuran. Adapaun hasil output pengujian reliabilitas menggunakan program SPSS versi 26 adalah sebagai berikut;

TABEL IX

UJI RELIABILITAS VARIABEL BUDAYA 5R (X1)

\begin{tabular}{|c|c|}
\hline Cronbach's Alpha & N of Items \\
\hline .664 & 6 \\
\hline
\end{tabular}

Berdasarkan data hasil uji reliabilitas pada Tabel IX bahwa nillai cronbach alpha adalah 0.664 atau bisa dinyatakan > 0.6. Hal ini menunjukkan bahwa indikator budaya $5 \mathrm{R}$ (X1) yang digunakan memiliki reliabilitias yang baik.

TABEL $X$

UJI RELIABILITAS VARIABEL KINERJA KARYAWAN (X2)

\begin{tabular}{|c|c|}
\hline Cronbach's Alpha & N of Items \\
\hline .647 & 6 \\
\hline
\end{tabular}

Berdasarkan data hasil uji reliabilitas pada Tabel X bahwa nillai cronbach alpha adalah 0.647 atau bisa dinyatakan > 0.6. Hal ini menunjukkan bahwa indikator kinerja karyawan (X2) yang digunakan memiliki reliabilitias yang baik.
TABEL XI

Uji Reliabilitas Variabel LingKUnGan KeRJa (Y)

\begin{tabular}{|c|c|}
\hline Cronbach's Alpha & N of Items \\
\hline .651 & 6 \\
\hline
\end{tabular}

Berdasarkan data hasil uji reliabilitas pada Tabel XI bahwa nilai cronbach alpha adalah 0.651 atau bisa dinyatakan > 0.6. Hal ini menunjukkan bahwa indikator lingkungan kerja (Y) yang digunakan juga memiliki reliabilitias yang baik..

\section{Uji Korelasi}

Dalam analisis kolerasi yang dicari adalah koefisien korelasi yaitu angka yang menyatakan derajat hubungan antara variabel independen $(\mathrm{X})$ dengan variabel dependen (Y) atau untuk mengetahui kuat atau lemahnya hubungan antara variabel independen dengan variabel dependen.

Berikut ini adalah hasil dari uji korelasi yang diolah dengan menggunakan SPSS.

TABEL XII

UJI KORELASI VARIABEL BUDAYA 5R (X1) DAN KINERJA KARYAWAN (X2) TERHADAP LINGKUNGAN

\begin{tabular}{|c|c|c|c|c|}
\hline \multicolumn{5}{|c|}{ KERJA (Y) } \\
\hline & & $\begin{array}{c}\text { Budaya } \\
5 R\end{array}$ & $\begin{array}{c}\text { Kinerja } \\
\text { Karyawan }\end{array}$ & $\begin{array}{c}\text { Lingkungan } \\
\text { Kerja }\end{array}$ \\
\hline \multirow[t]{3}{*}{ Budaya 5R } & Pearson & 1 & .195 & $.457^{* *}$ \\
\hline & $\begin{array}{l}\text { Correlation } \\
\text { Sig. (2- } \\
\text { tailed) }\end{array}$ & & .184 & .001 \\
\hline & $\mathrm{N}$ & 48 & 48 & 48 \\
\hline \multirow{4}{*}{$\begin{array}{c}\text { Kinerja } \\
\text { Karyawan }\end{array}$} & Pearson & .195 & 1 & $.842^{* *}$ \\
\hline & Correlation & & & \\
\hline & $\begin{array}{l}\text { Sig. (2- } \\
\text { tailed) }\end{array}$ & .184 & & .000 \\
\hline & $\mathrm{N}$ & 48 & 48 & 48 \\
\hline \multirow{4}{*}{$\begin{array}{c}\text { Lingkungan } \\
\text { Kerja }\end{array}$} & Pearson & $.457^{* *}$ & $.842^{* *}$ & 1 \\
\hline & Correlation & & & \\
\hline & $\begin{array}{l}\text { Sig. (2- } \\
\text { tailed) }\end{array}$ & .001 & .000 & \\
\hline & $\mathrm{N}$ & 48 & 48 & 48 \\
\hline
\end{tabular}

**. Correlation is significant at the 0.01 level (2-tailed).

Berdasarkan hasil output SPSS pada tabel XII, diketahui bahwa nilai pearson correlation pada variabel budaya $5 R$ adalah 0,457 maka dapat diinterpretasikan bahwa koefisien korelasi antara budaya 5R terhadap lingkungan kerja adalah sedang karena nilai tersebut berada di kisaran $(0.400-0,599)$ dan variabel kinerja karyawan adalah 0,842 maka dapat diinterpretasikan bahwa koefisien korelasi antara kinerja karyawan terhadap lingungan kerja adalah sangat kuat karena nilai tersebut berada di kisaran $(0.800-$ $1,000)$.

Untuk mengetahui korelasi antara budaya $5 \mathrm{R}$ (X1) dan kinerja karyawan (X2) terhadap 
lingkungan kerja (Y) dapat dihitung dengan cara sebagai berikut:

$$
\begin{aligned}
& r_{z=1 . x}=\sqrt{\frac{(0,457)^{2}+(0,842)^{2}-2(0,457)(0,842)(0,384)}{1-(0,384)^{2}}} \\
& r_{y=1 . x z}=\sqrt{\frac{(0,208)+(0,708)-(0,768)(0,384)}{1-(0,384)}} \\
& r_{x+1 . x z}=\sqrt{\frac{(0,621]}{0,616}} \\
& r_{p=1 . x z}=\sqrt{1,008} \\
& r_{y x 1 . x z}=1
\end{aligned}
$$

Berdasarkan hasil hitungan diatas telah didapatkan nilai korelasi antara budaya 5R (X1) dan kinerja karyawan (X2) terhadap lingkungan kerja (Y) sebesar 1, maka dapat diinterpretasikan bahwa koefisien korelasi antara budaya 5R (X1) dan kinerja karyawan (X2) terhadap lingkungan kerja (Y) adalah sangat kuat.

\section{E. Analisa Regresi}

\section{1) Analisa Koefisien Determinasi (R2)}

Uji koefisien determinasi bertujuan untuk melihat seberapa besar kemampuan variabel budaya 5R (X1) dan kinerja karyawan (X2) dalam menerangkan lingkungan kerja (Y) dapat dilakukan penghitungan keofisien determinasi (Kd) sebagai berikut:

$$
\begin{aligned}
K_{d} & =R^{2} \times 100 \% \\
& =(1)^{2} \times 100 \% \\
& =1 \times 100 \% \\
& =100 \%
\end{aligned}
$$

Berarti kemampuan budaya 5R dan kinerja karyawan dalam menerangkan lingkungan kerja sebesar $100 \%$ sehingga dapat dinyatakan variasi lingkungan kerja (Y) dapat dijelaskan oleh variasi dari variabel bebas yaitu budaya 5R (X1) dan kinerja karyawan (X2).

\section{2) Uji Signifikan simultan (Uji Statistik F)}

Uji F pada dasarnya menunjukan apakah semua variabel independen atau bebas yang dimasukan dalam model mempunyai pengaruh secara bersama-sama terhadap variabel dependen atau terikat.

Uji signifikansi simultan (uji statistik F) data budaya 5R (X1) dan kinerja karyawan (X2), didapat nilai $\mathrm{F}$ sebesar 88.567 dengan probabilitas adalah 0 (nol) sehingga dapat dikatakan bahwa budaya 5R (X1) dan kinerja karyawan (X2) secara bersama-sama berpengaruh terhadap lingkungan $\operatorname{kerja}(\mathrm{Y})$.
Uji signifikansi simultan (uji statistik F) data budaya 5R (X1) dan kinerja karyawan (X2) terhadap lingkungan kerja (Y) ditunjukan pada Tabel XIII.

TABEL XIII

UJI F BUDAYA 5R (X1) DAN KINERJA KARYAWAN (X2) TERHADAP LINGKUNGAN KERJA (Y)

\begin{tabular}{|c|c|c|c|c|c|c|}
\hline \multicolumn{8}{|c|}{ Model } & $\begin{array}{c}\text { Sum of } \\
\text { Squares }\end{array}$ & df & $\begin{array}{c}\text { Mean } \\
\text { Square }\end{array}$ & F & Sig. \\
\hline \multirow{3}{*}{1} & Regression & 281.223 & 2 & 140.612 & 88.567 & $.000^{\mathrm{b}}$ \\
\cline { 2 - 8 } & Residual & 71.443 & 45 & 1.588 & & \\
\cline { 2 - 8 } & Total & 352.667 & 47 & & & \\
\hline
\end{tabular}

\section{3) Uji Signifikan Parameter (Uji Statistik t)}

Uji t pada dasarnya menunjukkan seberapa jauh pengaruh suatu variabel penjelas atau independen secara individual dalam menerangkan variasi variabel dependen. Salah satu cara melakukan uji $\mathrm{t}$ adalah dengan membandingkan nilai statistik t dengan nilai kritis menurut tabel.

Uji signifikansi parameter (uji statistik t) pada

\begin{tabular}{|c|c|c|c|c|c|c|}
\hline & \multirow{2}{*}{ Model } & \multicolumn{2}{|c|}{$\begin{array}{c}\text { Unstandardized } \\
\text { Coefficients }\end{array}$} & \multirow{2}{*}{\begin{tabular}{|c}
$\begin{array}{c}\text { Standardized } \\
\text { Coefficients }\end{array}$ \\
Beta
\end{tabular}} & \multirow{2}{*}{$\mathbf{T}$} & \multirow{2}{*}{ Sig } \\
\hline & & B & $\begin{array}{c}\text { Std. } \\
\text { Error }\end{array}$ & & & \\
\hline \multirow[t]{2}{*}{1} & $\begin{array}{c}\text { Budaya } \\
5 \mathrm{R}\end{array}$ & .299 & .067 & .304 & 4.448 & .000 \\
\hline & $\begin{array}{c}\text { Kinerja } \\
\text { Karyawan }\end{array}$ & .851 & .074 & .782 & 11.435 & .000 \\
\hline
\end{tabular}
tabel XIV dibawah menyatakan bahwa budaya 5R (X1) dan kinerja karyawan (X2) terhadap lingkungan kerja (Y) signifikan pada 0 (nol) sehingga dapat disimpulkan bahwa variabel lingkungan kerja (Y) dipengaruhi oleh budaya 5R (X1) dan kinerja karyawan (X2).

TABEL XIV

UJI T BUDAYA 5R (X1) DAN KINERJA KARYAWAN

\section{PEMBAHASAN}

Perilaku budaya 5R (X1) dan kinerja karyawan (X2) secara bersama-sama berpengaruh terhadap lingkungan kerja (Y) di sinter plant PT. PT. XYZ. Data ini di dapat berdasarkan pengolahan data menggunakan uji korelasi, uji koefisien determinasi $\left(\mathrm{R}^{2}\right)$, uji signifikan simultan (uji statistik F) dan uji signifikan parameter (uji statistik t).

Perusahaan harus dapat meningkatkan perilaku budaya 5R dan kinerja karyawan agar lingkungan kerja di sinter plant PT. XYZ menjadi aman, selamat, produktif, efisien dan berkualitas sehingga dapat meningkatkan daya saing perusahaan di ruang lingkup industrinya. 


\section{KESIMPULAN}

Berdasarkan teori-teori yang melandasi rumusan permasalahan yang ada dalam penelitian ini serta hasil pengamatan, dokumentasi dan hasil keluaran dari program statistik SPSS yang sudah dihimpun dan diolah, dapat diambil kesimpulan sebagai berikut:

1. Semua indikator-indikator yang digunakan dalam penelitian ini memiliki keabsahan (validitas) dan keandalan (reliabilitas) yang baik.

2. Hasil analisa uji korelasi menyatakan bahwa korelasi antara budaya 5R (X1) dan kinerja karyawan (X2) terhadap lingkungan kerja (Y) adalah sangat kuat

3. Hasil analisa uji koefisien determinasi $\left(\mathrm{R}^{2}\right)$ menyatakan bahwa variasi lingkungan kerja (Y) dapat dijelaskan oleh variasi dari variabel bebas yaitu budaya 5R (X1) dan kinerja karyawan (X2).

4. Hasil analisa uji signifikan simultan (uji statistik F) menyatakan bahwa data budaya 5R (X1) dan kinerja karyawan (X2), didapat nilai $F$ sebesar 88.567 dengan probabilitas adalah 0 (nol) sehingga dapat dikatakan bahwa budaya 5R (X1) dan kinerja karyawan (X2) secara bersamasama berpengaruh terhadap lingkungan kerja (Y).

5. Hasil analisa uji signifikan parameter (uji statistik t) menyatakan bahwa budaya $5 \mathrm{R}$ (X1) dan kinerja karyawan (X2) terhadap lingkungan kerja (Y) signifikan pada 0 (nol) sehingga dapat disimpulkan bahwa variabel lingkungan kerja (Y) dipengaruhi oleh budaya 5R (X1) dan kinerja karyawan (X2).

\section{REFERENSI}

[1] Tampubolon, V. B. (2008). Evaluasi penerapan budaya kerja 5S di PT. AKM.

[2] Osada, T. (2004). Sikap kerja 5S. Jakarta: Penerbit PPM.

[3] Rimawan, Sutowo. 2015. Analisa Penerapan 5s+Safety Pada Areawarehouse di PT. Multifilling Mitra Indonesia. Jurnal Ilmiah PASTI Volume VI Edisi 1ISSN 2085-5869.

[4] Jahja, K. (2009). Seri Budaya Unggulan 5R (Ringkas, Rapi, Resik, Rawat, Rajin). Jakarta: Penerbit PPM.

[5] Irawan, P. (2000). Manajemen sumber daya manusia. STIA-LAN Press, Jakarta.

[6] Khairul Umam. (2018). "Pengaruh Gaya Kepemimpinan dan Lingkungan Kerja Terhadap Kinerja Karyawan. Skripsi. Serang: Universitas Serang Raya Serang.

[7] Sunyoto, D. (2007). Analisis Regresi dan Korelasi Bivariat.

[8] BadanPenerbit. Universitas Diponegoro: Semarang. 2016.

[9] Arikunto, S. (2006). Prosedur Penelitian Suatu Pendekatan. Jakarta: Rineka Cipta.
[10] Sugiyono, D. (2010). Metode penelitian kuantitatif kualitatif dan R\&D. XIII.

[11] Ghozali, Imam. Aplikasi SPSS. Cetakan IV. 